\title{
Not just folk medicine: myofascial cupping in the tech age!
}

\section{Mini Review}

You saw it on the Olympian swimmers in the 2016 Games, on Michael Phelps, on the backs of actresses sashaying down the red carpet, including Gwyneth Paltrow, Jessica Simpson, Victoria Beckham, Jennifer Aniston, and David Arquette. Serena Williams, Justin Bieber and Kim Kardashian also joined the "new" trend in experiencing this ancient modality. Those blotchy red or purple marks and perfect circles are the tell-tale of the cupping procedures familiar to practitioners of Asian and traditional bodywork and folk medicine, used for centuries. History indicates cupping was used centuries ago in ancient Asia, China, (Ge Hong) Egypt, (Ebers Papyrus), and Greece (Hippocrates). The original cups were hollowed horns or bones of animals and bamboo plants, used to suck out toxins from snakebites and insect venom. Over the years, practitioners of Traditional Chinese Medicine have used glass fire-cups combined with acupuncture or even bloodletting (wet cupping) for a variety of clinical conditions. Over time the cups were refined to produce the ones we use today, composed of glass, plastic, rubber, or silicone. Western clinicians are now using cupping as a manual therapy or soft tissue release tool, such as foam rollers, massage balls, and stretch bands. The procedure is known as dry cupping. Let's take a look at some of the recent evidence-based literature regarding the effects of dry cupping.

In a randomized controlled trial (RCT) of 70 soccer players, Fousekis et al. ${ }^{1}$ compared the results of three interventions on myofascial trigger point pain in the low back: instrument-assisted soft tissue mobilization, static dry cupping and ischemic pressure, applied once weekly for 3 weeks. All interventions demonstrated a significant improvement in pressure pain thresholds, although the former showed the most improvement. ${ }^{1}$ In a RCT of 50 patients with chronic neck pain, Saha et al. ${ }^{2}$ showed improved function, mental health, quality of life and decreased pain after five 10-minute sessions of gliding cupping over two weeks. ${ }^{2}$ Cao et al. ${ }^{3}$ published a systematic review of clinical evidence for cupping therapy in 2015 . They reported a need for additional rigorous studies since the ones reviewed showed either inadequate methodological quality or an insufficient number of trials. For the trials meeting established criteria for inclusion the systematic review, they found that cupping therapy was superior to interventions including medications for conditions such as low back pain and cervical spondylosis, facial paralysis, acne and herpes zoster. ${ }^{3}$ In a single blind RCT in 60 subjects with chronic neck and shoulder pain, Chi et al. ${ }^{4}$ reported a significant reduction in neck pain intensity and elevation in skin surface temperature after a single treatment of 10 minutes of static fire cupping bilaterally to three acupuncture points (SI15, GB21, LI15, in upper trapezius and deltoid). ${ }^{4}$

Markowski et al. ${ }^{5}$ reported significant improvement in low back pain, range of motion, and leg raise in 21 subjects given cupping with four pressurized cups over the low back. ${ }^{5}$ These are just a sample of the studies available on cupping therapy. Rozenfeld and Kalichman provided a summary of cupping methods and literature review, in which they discussed the physiological effect of cupping, including increased circulation, immune system activation, lymphatic
Volume II Issue I - 2019

\author{
Theresa A Schmidt \\ Department of physical therapy, Educise Resources Inc, USA
}

Correspondence: Theresa A Schmidt, DPT, MS, OCS, LMT, Educise Resources Inc P.O. Box 643, Northport, NY I I 768, USA, Tel 877-28I-3382, Fax 877-28I-3382, Email Educise@yahoo.com

Received: July 15, 2017 | Published: January 29, 2019

flow enhancement, mechanoreceptor stimulation with resultant reduction in nociceptive input and gating of pain. Several studies demonstrated the efficacy of cupping for a variety of musculoskeletal conditions. More research is advised to determine the mechanisms involved in the physiological response to cupping, and to compare the effects of cupping to other standard interventions used to manage musculoskeletal dysfunction. ${ }^{6-22}$

\section{Conflicts of interest}

None.

\section{Acknowledgment}

None.

\section{References}

1. Fousekis K. The Effectiveness of Instrument-assisted Soft Tissue Mobilization Technique (Ergon (C) Technique), Cupping and Ischaemic Pressure Techniques in the Treatment of Amateur Athletes' Myofascial Trigger Points. Journal of Novel Physiotherapies. 2016.

2. Saha FJ, Schumann S, Cramer H, et al. The Effects of Cupping Massage in Patients with Chronic Neck Pain - A Randomized Controlled Trial. Complement Med Res. 2017;24(1):26-32.

3. Cao H, Han M, Zhu X, et al. An overview of systematic reviews of clinical evidence for cupping therapy. Journal of Traditional Chinese Medical Sciences. 2015;2(1):3-10.

4. Chi LM, Lin LM, Chen CL, et al. The Effectiveness of Cupping Therapy on Relieving Chronic Neck and Shoulder Pain: A Randomized Controlled Trial. Evid Based Complement Alternat Med. 2016;2016:7358918.

5. Markowski A, Sanford S, Pikowski J, et al. A Pilot Study Analyzing the Effects of Chinese Cupping as an Adjunct Treatment for Patients with Subacute Low Back Pain on Relieving Pain, Improving Range of Motion, and Improving Function. J Altern Complement Med. 2014;20(2):113117.

6. Ahmed A. Innovative Energy Standard of Curative Cupping/Hijama. Journal of Basic \& Applied Sciences. 2015;11:445-453.

7. Akbarzade M, Ghaemmaghami M, Yazdanpanahi Z, et al. Comparison of the Effect of Dry Cupping Therapy and Acupressure at BL23 Point on Intensity of Postpartum Perineal Pain Based on the Short Form of McGill Pain Questionnaire. J Reprod Infertil. 2016;17(1):39-46. 
8. Al Bedah Abdullah MN, Khalil Mohamed KM, Posadzki Paul, et al Evaluation of Wet Cupping Therapy: Systematic Review of Randomized Clinical Trials. The Journal of Alternative and Complementary Medicine. 2016;22(10):768-777.

9. Cobian D. Cupping: Why We're All Seeing Spots. American Physical Therapy Association. 2016.

10. Dons'koi BV, Chernyshov VP1, Osypchuk DV, et al. Cupping manipulation temporary decreases natural killer lymphocyte frequency, activity and cytotoxicity. J Integr Med. 2016;14(3):197-202.

11. Farhadi K, Choubsaz M, Setayeshi K, et al. The effectiveness of drycupping in preventing post-operative nausea and vomiting by P6 acupoint stimulation: A randomized controlled trial. Medicine (Baltimore) 2016;95(38):e4770.

12. Gok S, Kazanci FH, Erdamar H, et al. Is it possible to remove heavy metals from the body for wet cupping therapy (Al-hijamah?) Indian Journal of Traditional Knowledge. 2016;15(4):700-704.

13. Koh KS, Park SW, Oh TS, et al. Flap preconditioning by pressurecontrolled cupping in a rat model. J Surg Res. 2016;204(2):319-325.

14. Kurniawan D, Darsini, Udaya M. Effect of Changes Cupping Therapy In The Elderly With Joint Pain Rheumatoid Arthritis (Study In Upt Pslu Jombang). Nursing Journal of Stikes Insan Cendekia Medika Jombang. 2013;5(1):13-18.

15. Lauche R, Spitzer J, Schwahn B, et al. Efficacy of cupping therapy in patients with the fibromyalgia syndrome-a randomized placebo controlled trial. Sci Rep. 2016; 6:37316.
16. Li T, Li K. A noninvasive device for simultaneous monitoring arterial and venous blood oxygenation and its test in vacuum-based cupping therapy. International Nanoelectronics Conference (INEC). 2016:1-2.

17. Pan L, Ma X-hong, Han S, et al. Comparative Study on the Therapeutic Efficacy between Medicinal Cupping and Bloodletting for Chronic Low Back Pain. Shanghai Journal of Acupuncture and Moxibustion. 2016;35(9):1112-1114.

18. Roostayi M, Norouzali T, Manshadi F, et al. The Effects of Cupping Therapy on Skin's Biomechanical Properties in Wistar Rats. Chinese Medicine. 2016;25-30.

19. Rozenfeld E, Kalichman L. New is well-forgotten old: The use of dry cupping in musculoskeletal medicine. J Bodyw Mov Ther. 2016;20(1):173-178

20. Tarek S. Effects of Cupping Therapy Based on Stabilization Core Exercises On Low Back Pain For Soccer Players In State Of United Arab Emirates. Science, Movement and Health. 2016;16(2):684-690.

21. Ting Li, Yaoxian Li, Yu Lin, et al. Significant and sustaining elevation of blood oxygen induced by Chinese cupping therapy as assessed by nearinfrared spectroscopy. Biomed Opt Express. 2016;8(1):223-229.

22. Wang B, Liu X, Hu Z, et al. YANG's pricking-cupping therapy for knee osteoarthritis: a multi-center randomized controlled trial. Zhongguo Zhen Jiи. 2016;36(2):113-118. 